\title{
Massive reduction of tumour load and normalisation of hyperprolactinaemia after high dose cabergoline in metastasised prolactinoma causing thoracic syringomyelia
}

\author{
S H M van Uum, N van Alfen, P Wesseling, E van Lindert, G F F M Pieters, P Nooijen, \\ A R M M Hermus
}

In 1970 a 20 year old woman presented with a pituitary chromophobe adenoma for which she underwent transfrontal pituitary surgery. In 1978 she had to be reoperated on because of local tumour recurrence, resulting in hypopituitarism. Bromocriptine ( $5 \mathrm{mg} /$ day) was given for 15 years, but the plasma prolactin levels remained elevated. In 2000 the patient presented with signs and symptoms suggestive of a spinal cord lesion at the mid-thoracic level. A magnetic resonance imaging (MRI) scan showed an extensive leptomeningeal mass extending from the brainstem to $L 5$, with a thoracic syringomyelia at the T7-T8 level. The plasma prolactin level was very high (5114 $\mu \mathrm{g} / \mathrm{l})$. A biopsy showed the presence of a metastasised prolactinoma.

On administration of high dose cabergoline, $0.5 \mathrm{mg}$ twice a day orally, the plasma prolactin levels decreased within one month and then normalised within 26 months. Tumour load reduced considerably but unfortunately, her signs and symptoms did not improve. This case illustrates that a high dose dopamine agonist might be an important therapeutic option in patients with a metastasised prolactinoma.

M alignant prolactinoma, defined as a prolactin secreting pituitary adenoma with subsequent metastatic spread to extrapituitary cerebrospinal sites or to organs outside the central nervous system, is a rarity. Only six cases of malignant prolactinoma metastasising to the spinal cord have been reported in the literature. We describe a patient with a prolactinoma that metastasised to the spinal cord who presented with neurological symptoms due to thoracic syringomyelia. This patient is unusual because during therapy with high dose cabergoline there was massive reduction of her tumour load and complete normalisation of the hyperprolactinaemia.

\section{CASE REPORT}

A 50 year old woman was referred in March 2000 because of pain and sensory disturbances in her legs. In 1970 she had undergone transcranial pituitary surgery via a subfrontal approach for a chromophobe adenoma. Plasma prolactin was first measured in 1974 and found to be $180 \mu \mathrm{g} / \mathrm{l}$ (upper limit of normal $20 \mu \mathrm{g} / \mathrm{l}$ ). In 1978 she presented with visual disturbances. Her plasma prolactin level was $115 \mu \mathrm{g} / \mathrm{l}$. She again underwent transcranial pituitary surgery, which resulted in hypopituitarism and for which replacement therapy was initiated. Bromocriptine $5 \mathrm{mg}$ /day was started, but the prolactin levels remained elevated.
In 1993, a magnetic resonance imaging (MRI) study of the brain and spinal cord did not show any abnormality in the sellar region, but did reveal multiple small areas of increased density around the medulla oblongata and the spinal cord, and between the cerebellum and cerebral peduncles. The lesions showed contrast enhancement with gadolinium. At that time the lesions were ascribed to Lipiodol used during previous myelographic studies. Since the patient had no complaints and there was no evidence of local recurrence, bromocriptine was discontinued. This resulted in an increase of plasma prolactin from $650 \mu \mathrm{g} / \mathrm{l}$ to $1280 \mu \mathrm{g} / \mathrm{l}$. The prolactin level further increased to $7858 \mu \mathrm{g} / \mathrm{l}$ in 1999.

In 1998 the patient experienced numb, tight sensations in the fourth and fifth digits of the left foot. In April 1999 she developed pain in the left subscapular area and from October 1999 she noted icy and frozen sensations below the waist, with tingling sensations in both legs. These symptoms slowly progressed to a level where she had to visually guide herself when moving around. In addition, there were spontaneous kicking movements of the legs and micturition was impaired with urge incontinence. Her medication at that time consisted of cortisone acetate $37.5 \mathrm{mg} /$ day, levothyroxine $0.05 \mathrm{mg} /$ day and a combination of estradiol and norgestrel.

Physical examination at referral showed an alert, well oriented woman. There was increased muscle tone in the legs, and a partial drop foot on the left (MRC grade 4). She had a broad stance and gait and tandem walking was impossible. There was hypaesthesia below T9 level for both pinprick and position sense; Romberg's sign was positive. There was hyperreflexia of the knee and ankle jerks. Abdominal cutaneous reflexes were absent at all levels. Plantar responses were normal. The symptomatology was most consistent with a spinal cord lesion at the mid-thoracic level.

Laboratory investigations revealed an extremely high level of plasma prolactin $(5114 \mu \mathrm{g} / \mathrm{l})$. On lumbar puncture the opening pressure was $14 \mathrm{~cm} \mathrm{H}_{2} \mathrm{O}$, and the viscous, yellow cerebrospinal fluid (CSF) flowed with difficulty. Fluid analysis showed 11 leucocytes/ $\mu \mathrm{l}, 8$ erythrocytes/ $\mu$, a hugely elevated protein content of $19500 \mathrm{mg} / \mathrm{l}$, glucose $1.9 \mathrm{mmol} / \mathrm{l}$ (serum value $4.2 \mathrm{mmol} / \mathrm{l}$ ), and lactate $5645 \mu \mathrm{mol} / \mathrm{l}$. This, and a negative Queckenstedt's test, suggested a spinal subarachnoid block of CSF flow. Due to the limited amount of CSF obtained, no cytological studies were done and prolactin levels were not measured.

An MRI study of the whole cerebrospinal system was done (fig 1A, C). No tumour recurrence was found in the sellar

Abbreviations: CSF, cerebrospinal fluid; MRI, magnetic resonance imaging; MRC, Medical Research Council 

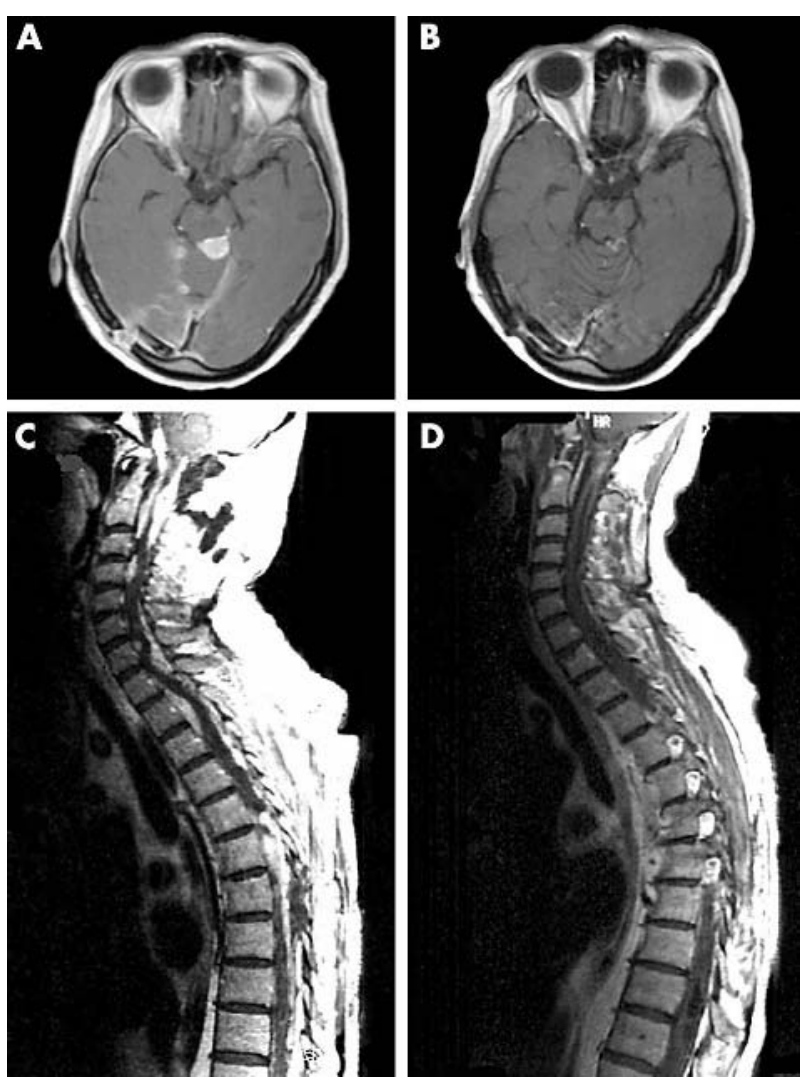

Figure $1 \mathrm{Tl}$ axial, gadolinium enhanced, magnetic resonance imaging (MRI) scan of the brain and T1 sagittal, gadolinium enhanced, MRI scan of the spinal cord before $(A, C)$ and after $(B, D)$ high dose cabergoline for 26 months.

region, but an extensive leptomeningeal mass surrounding and slightly compressing the brainstem extended throughout the intrathecal space down to the level of L5. Further, there was thoracic syringomyelia at the T7-T8 level.

Occipitocervical decompression was performed and a biopsy of the tumour mass surrounding the medulla oblongata was taken. Microscopic examination showed adenomatous tissue with closely packed monomorphous cells and a low mitotic index. The immunohistochemical staining for prolactin was strongly positive. A diagnosis of malignant prolactinoma with metastasis to the leptomeninges was made.

In an attempt to improve or stabilize the patient's symptoms a thoracic laminectomy at $\mathrm{T} 7$ with insertion of a syringosubarachnoidal CSF shunt was performed one week after the biopsy was taken. During the procedure extensive adhesions of the arachnoids and dura were found, with hardly any flow of CSF from the subarachnoid space. An arachnoid pseudocyst, which was compressing the spinal cord was laterally opened and drained. In the midline, a tumour, several millimetres thick extending over a bulging spinal cord, was removed, and following incision of the spinal cord the CSF discharged under pressure emptying the syrinx. Subsequently, the spinal cord tissue collapsed. A small catheter was inserted in the syringeal cavity.

Unfortunately the patient's difficulties with walking and her sensory disturbances did not improve after surgery. A week later an emergency ventriculoperitoneal shunt had to be placed because of acute obstructive hydrocephalus.

High dose cabergoline $(0.5 \mathrm{mg}$ twice a day orally) was started after the first operation. The plasma prolactin level decreased quickly and was below $300 \mu \mathrm{g} / \mathrm{l}$ within a month. Thereafter the prolactin level normalised and remained normal throughout the treatment which continued for 26 months. Treatment was well tolerated, and the patient did not show any further decline. She was discharged to a rehabilitation facility. MRI studies of the cerebrospinal system were repeated after four months. The tumour had decreased in size at the level of both the medulla oblongata and the spinal cord. Repeat MRI studies after treatment for 26 months showed a considerable, further decrease in tumour load (fig 1B, D).

Despite the impressive effect of cabergoline on plasma prolactin levels and tumour load, the patient continued to have disabling neuropathic pains in her legs and decreased sensibility below the T7 level, severely complicating her walking. Two years after the surgery she remains wheelchair dependent.

\section{DISCUSSION}

Our patient presented with a chromophobe pituitary adenoma in 1970, with local recurrence in 1978. Retrospectively, metastatic tumour deposits along the neuraxis were already present at least since 1993. When we first saw her 30 years after the first pituitary surgery, her neurological symptoms were not due to direct compression of the central nervous system by tumour metastases, but to blockage of CSF flow by arachnoid adhesions caused by metastatic tumour deposits and the subsequent formation of a thoracic syringomyelia.

Malignant prolactinomas are very rare. The first case was described in 1981 by Martin et al. ${ }^{1}$ Until now about 30 cases of metastasising prolactinoma have been described. The interval between the initial presentation of the prolactinoma, usually with a sellar tumour, and the diagnosis of the metastasised prolactinoma varies from two months to 27 years, with an average of seven years. ${ }^{2}$ Results of treatment of metastasised prolactinoma are generally poor. Surgery, radiation therapy, chemotherapy, and treatment with dopamine agonists either alone or, more commonly, in various combinations resulted in no, or only a partial, temporary response in almost all cases. $^{34}$

Our patient presented with metastases in spinal cord from a malignant prolactinoma resulting in a syrinx. Intraspinal metastases have been described previously in six patients with a malignant prolactinoma, ${ }^{25-9}$ but a syrinx, such as in our patient, was not present in any of them. Two patients died before the effect of therapy could be assessed. ${ }^{78}$ One patient had signs and symptoms due to a metastasis at $\mathrm{Ll}$ level. ${ }^{5}$ A combination of surgery, radiotherapy, bromocriptine, and anti-oestrogen therapy, resulted in stabilisation, but there was no improvement in the neurological situation and a decrease of prolactin of only about $50 \%$. Another patient with a single intraspinal metastasis from a prolactinoma at the level of S1-S2 was successfully treated with surgery, radiation, and bromocriptine. ${ }^{2}$ Kuroki et al described a patient with multiple intradural masses on myelography, most probably metastases from a prolactinoma. ${ }^{6}$ Radiation resulted in improvement of severe low back pain, but the patient died within three months because of regrowth of intracranial lesions. The sixth patient presented with multiple prolactinoma lesions from the foramen magnum to L3. After biopsy of the largest nodule and radiation therapy the myelopathic symptoms considerably improved while on bromocriptine $100 \mathrm{mg}$ daily. ${ }^{9}$

Our patient had a large intraspinal tumour burden extending from the medulla oblongata to the lumbar region, which made curative surgery impossible. As we were concerned that radiotherapy would further damage the vulnerable neural tissue around the syrinx, we decided to treat the patient with a dopamine agonist only. In the past, 
the plasma prolactin had increased during treatment with low dose bromocriptine ( $5 \mathrm{mg}$ daily). We therefore selected another dopamine agonist, cabergoline, and because of the huge tumour load we chose a high dose, $0.5 \mathrm{mg}$ twice a day orally (normal starting dose for a macroprolactinoma is $0.5 \mathrm{mg}$ twice weekly). Our patient is the first reported patient with a metastasised prolactinoma in whom monotherapy with a dopamine agonist resulted in complete normalisation of the plasma levels of prolactin. This treatment also resulted in a decrease of tumour size, first documented after four months with further reduction seen after two years. The high dose cabergoline was very well tolerated and we conclude that this might be an important therapeutic option in patients with a metastasised prolactinoma.

\section{Authors' affiliations}

S H M van Uum, G F F M Pieters, A R M M Hermus, Department of Endocrinology, University Medical Center Niijmegen, Nijmegen, the Netherlands

$\mathrm{N}$ van Alfen, Department of Neurology, University Medical Center Nijmegen, Nijmegen, the Netherlands P Wesseling, P Nooijen, Department of Pathology, University Medical Center Nijmegen, Nijmegen, the Netherlands E van Lindert, Department of Neurosurgery, University Medical Center Nijmegen, Nijmegen, the Netherlands

Competing interests: none declared
Correspondence to: S H M van Uum, MD, PhD, Assistant Professor, Endocrinology and Metabolism, St Joseph's Health Centre, Room G401, 268 Grosvenor St, London, Ontario, Canada, N6A 4V2;

Stan.VanUum@sjhc.london.on.ca

Received 12 September 2003

In revised form 24 December 2003

Accepted 28 December 2003

\section{REFERENCES}

1 Martin NA, Hales M, Wilson CB. Cerebellar metastasis from a prolactinoma during treatment with bromocriptine. J Neurosurg 1981;55:615-19.

2 Popadic A, Witzmann A, Buchfelder M, et al. Malignant prolactinoma: case report and review of the literature. Surg Neurol 1999;51:47-54.

3 Walker JD, Grossman A, Anderson JV, et al. Malignant prolactinoma with extracranial metastases: a report of three cases. Clin Endocrinol (Oxf) 1993;38:411-19.

4 Kaltsas GA, Mukherjee JJ, Plowman PN, et al. The role of cytotoxic chemotherapy in the management of aggressive and malignant pituitary tumors. J Clin Endocrinol Metab 1998;83:4233-8.

5 Landgraf $\mathbf{R}$, Rieder $G$, Schmiedek $P$, et al. Hormone-active intradural spinal metastasis of a prolactinoma-a case report. Klin Wochenschr 1985;63:379-84

6 Kuroki M, Tanaka R, Yokoyama M, et al. Subarachnoid dissemination of a pituitary adenoma. Surg Neurol 1987;28:71-6.

7 Popovic EA, Vattuone JR, Siu KH, et al. Malignant prolactinomas. Neurosurgery 1991;29:127-30.

8 Kamphorst W, Wolbers JG, Ponssen H, et al. Ectopic parasellar pituitary adenoma with subarachnoid seeding. J Neurol Neurosurg Psychiatry 1992;55:73-4.

9 Rockwell BH, Pica R, Raji MR, et al. Intrathecal metastatic pituitary prolactinoma. Am J Roentgenol 1996;167:1295-6. 